- RAM, REV. ADM. MACKENZIE, V. 11, N. 5 • SÃO PAULO, SP • SET./OUT. 2010 - ISSN 1678-6971 •

Submissão: 11 abr. 2009. Aceitação: 3 maio 2010. Sistema de avaliação: às cegas dupla (double blind review). UNIVERSIDADE PRESBITERIANA MACKENZIE. Walter Bataglia (Ed.), p. 129-150.

\title{
O FIM DA INFÂNCIA? AS AÇÕES DE MARKETING E A “ADULTIZAÇÃO” DO CONSUMIDOR INFANTIL
}

\section{CHILDHOOD'S END? MARKETING ACTIONS AND THE “PREMATURE ADULTHOOD” OF THE CHILD CONSUMER}

\author{
CARLA FREITAS SILVEIRA NETTO \\ Mestre em Administração pelo Programa de Pós-Graduação em Administração da \\ Pontifícia Universidade Católica do Rio Grande do Sul (PUC-RS). \\ Atendimento e Planejamento em Marketing e Comunicação da Comunicative - \\ Gestão de Posicionamento e Comunicação Ltda.
} Rua Itapeva, 90, sala 501/502, Passo da Areia - Porto Alegre - RS - Brasil - CEP 91350-080 E-mail: carla.netto@gmail.com

\section{VINÍCIUS ANDRADE BREI}

Doutor em Ciências de Gestão pela École des Hautes Études Commerciales, Paris, França.

Professor do Departamento de Ciências da Administração da

Universidade Federal de Santa Catarina (UFSC).

Campus Universitário Professor João David Ferreira Lima, Departamento de Ciências da Administração, sala 226, Trindade - Florianópolis - SC - Brasil - CEP 88040-900

E-mail: viniciusbrei@gmail.com

MARIA TEREZA FLORES-PEREIRA

Doutora em Administração pelo Programa de Pós-Graduação em Administração da

Universidade Federal do Rio Grande do Sul (UFGRS). Professora do Programa de Pós-Graduação em Administração da Pontifícia Universidade Católica do Rio Grande do Sul (PUC-RS). Avenida Ipiranga, 6.681, Prédio 50, sala 1.102, Partenon - Porto Alegre - RS - Brasil - CEP 90619-900 


\section{RESUMO}

O objetivo deste artigo é analisar criticamente as representações sobre a infância desenvolvidas nas ações de marketing de uma empresa de vestuário infantil, avaliando se estas podem contribuir para a "adultização" do consumidor infantil. O objeto de estudo foram as duas últimas campanhas de comunicação (outono/ inverno 2008 e primavera/verão 2008/2009) da Lilica Ripilica, uma conhecida marca no Brasil no segmento infantil feminino. Utilizamos a metodologia de análise crítica de discurso (FAIRCLOUGH, 200I), em três etapas: a análise textual (uma "descrição" dos textos), a análise processual (análise conjunta dos textos e da prática discursiva) e a análise social (compreensão dos efeitos socioculturais da prática discursiva). Os resultados de tal análise demonstram que o discurso da marca procura "ensinar" às crianças padrões de beleza e de comportamentos associados ao mundo adulto, o que reforça a indissociação criança/adulto. Esse fenômeno já foi identificado em literatura acerca da Idade Média (ARIÈS, I98I). A contribuição deste trabalho se refere à observação dessa mesma indissociação, porém, a partir de outra perspectiva: a "adultização" de crianças como forma de sociabilização destas para o mercado de consumo. A pesquisa mostra que um novo modelo de adulto em miniatura parece se construir mediado pelas ações de marketing.

\section{PALAVRAS-CHAVE}

Infância; “Adultização”; Análise crítica de discurso; Comunicação; Marketing.

\section{ABSTRACT}

The main purpose of this paper is to critically analyze childhood representations that appear in a children clothes company's marketing actions, to reach an understanding of this actions' contribution to the "premature adulthood" of the child consumer. We analyze two communication campaigns (Autumn/Winter 
2008 and Spring/Summer 2008/2009) of Lilica Ripilica, a well-known brand in the Brazilian children market. To do this we use the method of critical discourse analysis (FAIRCLOUGH, 200I), in three stages: textual analysis (a "discription" of the texts); processual analysis (analyzing texts and the discourse practice); and social analysis (understanding the social and cultural effects of the discourse practice). As a result, our analyzes reveal that the brand's discourse aims to "teach" children beauty standards and behaviours that are related to the adult world, something which reinforces the indissociation between child/adult. A similar reality was indentified in the Middle Age literature (ARIÈS, I98I). This paper's contribution involves the observation of this same indissociation, but in a diferent perspective: the "premature adulthood" of children as a way of socialization in the consumer market. The research shows that a new model of miniature adult seems to be constructed by the actions of marketing.

\section{KEYWORDS}

Childhood; "Premature adulthood"; Critical discourse analysis; Communication; Marketing.

\section{INTRODUÇÃO}

Nossa sociedade valoriza a beleza, a moda e a fama na maior parte de suas expressões culturais: novelas, filmes, programas de televisão e, é claro, nas propagandas e na moda, instrumentos fundamentais para a construção de um sistema cultural (MCCRACKEN, I986). Essa supervalorização não é um fenômeno restrito aos adultos, ela também afeta sobremaneira as crianças.

Assim como outras categorias etárias, a infância se refere a uma fase de vida sócio-histórica e culturalmente construída. Na configuração de tal fase etária, estão presentes discursos, símbolos, significados e práticas que se constroem na ação cotidiana dos mais diversos agentes sociais, como a família, a escola, o Estado e, inclusive, a mídia.

Fenômenos sociais contemporâneos, enfatizando o caso brasileiro, mostram-nos como as fronteiras entre ser criança e ser adulto têm se tornado ambíguas. Fatos como a permanência de adultos (ou jovens) entre 25 e 40 anos na casa dos pais, o aumento da criminalidade infantil, o consumo de drogas (lícitas e ilícitas) cada vez mais cedo, violência de jovens contra pais e sociedade e, junto com esses problemas, a recente discussão sobre a redução da maioridade penal são ilustrativos desse contexto. Essas situações, pinçadas de um determinado 
conjunto social, demonstram que existe uma espécie de "borramento" acerca de algumas caracterizações tradicionais do que é ser criança e de qual é o período compreendido como categoria etária infância.

Um dos fatores que diferenciam a infância da idade adulta é o conhecimento (ARIÈS, I98I; POSTMAN, I999). Segundo Postman (I999), se as crianças tivessem o mesmo nível, ou maior, de conhecimento que os adultos, estes perderiam a autoridade. Nesse caso, analisa Postman (I999), o acesso cada vez maior à informação e ao conhecimento por parte das crianças reduziria a distância destas em relação ao "mundo" adulto. Trazendo mais especificamente a ideia de antecipação da vida adulta, Guerreiro e Abrantes (2005, p. I69) acreditam que "as fracas aspirações escolares, a entrada precoce no mercado de trabalho" estariam entre as razões que levam uma criança a transitar prematuramente por práticas (e obrigações) sociais tradicionalmente vinculadas à vida adulta. Tanto em uma situação como em outra, estaríamos perdendo uma referência de uma dissociação da sociedade de crianças e de adultos, pois os primeiros se tornariam crianças-adultos, ou seja, um ser híbrido em termos de maturidade.

Entretanto, as razões para a ocorrência desse "borramento" etário contemporâneo são múltiplas e mais complexas do que preveem os autores citados: a necessidade de os pais trabalharem, a falta de orientação dos jovens, a insegurança do mercado de trabalho, o acesso ainda limitado à educação, entre outros fatores socioeconômicos e culturais. Nosso foco neste artigo, entretanto, não é tão ambicioso. Pretendemos tão somente analisar o eventual papel do marketing, com destaque para as ações de comunicação, na constituição desse quadro de adultos precoces.

Embora as crianças formem um segmento fortemente atingido por ações mercadológicas, apenas recentemente o interesse em pesquisar o comportamento do consumidor infantil chegou à academia, especialmente à de marketing. Segundo John (I999, p. I83), os estudos tendo por foco a criança como consumidora somente "desabrocharam" em meados da década de I970. Essa recentidade causa estranheza, pois, sem entender as "crianças e a infância, ficamos deficientes na nossa habilidade para investigar o lugar dos bens materiais e da atividade comercial nas vidas sociais" (COOK, 2008, p. 227). Para Cook (2008), as teorias criadas e estudadas até hoje sobre o comportamento infantil tentam enquadrar as crianças em conceitos criados para os adultos. É como se as pessoas somente atingissem sua plenitude como consumidoras quando se tornassem adultas.

Assim, o objetivo deste artigo é analisar criticamente as representações de infância desenvolvidas em ações de comunicação de marketing, principalmente nas propagandas, como forma de avaliar se estas estão contribuindo para a indistinção das fases infantil e adulta da vida dos consumidores. Se, para estudar a imagem da infância na Idade Média, Ariès (I98I) recorreu à arte e à literatura, 
recorreremos, no início deste milênio, à análise da comunicação (principalmente da propaganda) para entendê-la, pois "a criança que habita romances e poemas é parente próxima da criança que em outdoors vende sabonetes ou planos de saúde” (LAJOLO, I997, p. 232-233). Mais especificamente, escolhemos como nosso objeto de estudo as duas últimas campanhas de comunicação de uma das marcas nacionais de maior destaque no segmento de vestuário infantil feminino, a Lilica Ripilica, da empresa Marisol S.A. Além de identificar o contexto social em que o discurso da marca se insere e de analisar as possíveis consequências para o público-alvo, pretendemos também contribuir para a literatura de marketing e de consumo. Buscamos, portanto, trazer para o contexto brasileiro uma pesquisa que aborde o consumidor infantil com base em um pensamento crítico e reflexivo da prática do marketing e da comunicação, tendo um foco maior para a propaganda.

Na próxima seção, apresentamos uma breve revisão da teoria sobre as crianças e o consumo. A seguir, delineamos os aspectos principais da pesquisa empírica realizada, para, então, apresentarmos os resultados e a discussão dos achados de campo. Concluímos o artigo com algumas reflexões sobre os possíveis efeitos da comunicação sobre as representações contemporâneas de infância, mais especificamente de uma infância do gênero feminino.

\section{TEORIA}

\subsection{AS MUDANÇAS DO CONCEITO DE INFÂNCIA A PARTIR DA IDADE MÉDIA}

O conceito de criança mudou ao longo da história (COWELL, 200I; ARIÈS, I98I; POSTMAN, I999). Por exemplo, Ariès (I98I), em seus estudos baseados na arte e na literatura europeia (com maior ênfase na França), mostra que, na Idade Média, não havia diferenciação de vestuário em função da faixa etária da pessoa. As diferenças ocorriam, apenas, para manter visíveis, por meio da roupa, os degraus da hierarquia social: "Nada, no traje medieval, separava a criança do adulto" (ARIÈS, I98I, p. 70).

Essa indiferenciação dos trajes era apenas um reflexo da falta de importância das crianças naquele momento histórico. Ariès (I98I, p. 50) afirma que "até por volta do século XII, a arte medieval desconhecia a infância ou não tentava representá-la". Analisando esculturas e pinturas, o autor cita que as crianças eram representadas apenas com uma estatura diferente dos adultos, apresentando roupas ou musculatura semelhantes às de adultos. Nem mesmo as idades ou os nomes das crianças eram registrados, pois os pais não tinham esperança de que muitos de seus filhos sobrevivessem e preferiam não se lembrar deles, mas "assim 
que a criança superava esse período de alto nível de mortalidade, em que sua sobrevivência era improvável, ela se confundia com os adultos" (ARIÈS, I98I, p. I57). Reforçando essa ideia, Heywood (2004) comenta que essa situação ocorria num contexto de uma sociedade pré-industrial, em que as crianças eram inseridas gradualmente no mundo dos adultos a partir de uma idade precoce, ajudando os pais, trabalhando na condição de servas ou desenvolvendo o aprendizado de um ofício.

No Brasil, durante a colônia e o império, a situação não era muito diferente. Durante a infância, a criança tinha dois caminhos básicos: quem tinha condições financeiras estudava aqui ou no exterior, e quem não tinha trabalhava. A infância era dividida em três estágios (PRIORE, 2000, p. 84-85): o primeiro ia até o final da amamentação (por volta dos 3 ou 4 anos); no segundo, até os 7 anos, as crianças cresciam à sombra dos pais, acompanhando-os nas tarefas do dia a dia. A partir do terceiro estágio, as crianças iam trabalhar, desenvolvendo pequenas atividades, estudavam, ou ainda aprendiam algum ofício, tornando-se "aprendizes". É apenas nessa última fase que os caminhos se bifurcavam: o estudo para os mais ricos e o trabalho para os mais pobres.

A descoberta da infância, segundo Postman (I999), ocorreu com a popularização dos livros; já para Ariès (I98I), com a expansão das escolas, ambos os eventos ocorridos entre os séculos XVI e XVII. Porém, os dois autores concordam que o conhecimento e a separação entre os que sabiam e os que não sabiam eram responsáveis pela criação tanto da infância quanto da idade adulta. Nas escolas, as crianças foram divididas em séries com diferentes uniformes, diferentes níveis de conhecimento e adquiriram também uma linguagem própria. Mas não apenas as escolas e os livros alteraram a noção de infância. Entre aqueles séculos, a sociedade mudou, tornou-se mais moralista, surgiram assuntos e livros proibidos para as crianças, e também "surgiu uma classe média visível e florescente, pessoas com dinheiro e o desejo de gastá-lo" (POSTMAN, I999, p. 58). E esse dinheiro era gasto com as crianças que, segundo Postman (I999), do século XVI em diante, se vestiam, falavam e viviam de forma distinta dos adultos. Entretanto, mais uma vez essa distinção entre adultos e crianças limitava-se a uma classe social específica, pois, nas fábricas, as crianças ainda trabalhavam como adultos. No vestuário, também a distinção se restringiu a algumas classes, especialmente as burguesas ou nobres. As crianças "do povo" continuaram a usar o mesmo traje dos adultos (ARIÈS, I98I, p. 8I).

A evolução do conceito de criança, portanto, seguiu uma ordem em que, primeiro, via-se a criança como um adulto em miniatura (POSTMAN, I999); depois, concebendo-a como um ser essencialmente diferente do adulto. A sociedade foi, portanto, adquirindo maior interesse pela criança e assumindo que "a responsabilidade pelo crescimento das crianças cabe aos adultos" (POSTMAN, I999, p. 78). Segundo Ariès (I98I), a família começou então a dar importância para a criança, organizando-se em função dela e tirando-a de seu anonimato. 
As representações de infância na sociedade contemporânea são diversas e também se diferenciam a partir de categorias como espaço e classe social. Uma das questões que chamam atenção, entretanto, é que para fins comerciais o que prevalece é certa ambiguidade na visão sobre as crianças. Por um lado, são vistas como desprotegidas e inocentes; sujeitas, portanto, às influências da propaganda. Por outro lado, são tratadas como consumidoras, com vontades e desejos próprios (CROSS, 2002). Se as crianças, por um lado, são protegidas pela lei de abusos, violência e do trabalho, por outro, vivem em uma sociedade que explora uma imagem de infância com comportamento adulto em seus produtos culturais, como as novelas, as músicas, os seriados de TV e a propaganda.

Então, se partirmos dos pressupostos de que as crianças têm o direito de fazer parte da sociedade de consumo e têm acesso à informação, elas também passam a ter direito, segundo a tese de Postman (1999), de ser adultos. Essa indissociação que o mundo comercial acaba por incitar na formação do consumidor infantil nos motiva a analisar empiricamente as ações de marketing de uma empresa de vestuário destinado a esse público, de modo a analisar criticamente se (e como) essa indissociação das fases infantil e adulta da vida dos consumidores se apresenta.

\subsection{AS CRIANÇAS, O CONSUMO E A PROPAGANDA}

Nas pesquisas sobre o comportamento do consumidor, Cook (2008) afirma que as crianças não têm - ou têm pouco - espaço nas teorias desenvolvidas; essas teorias têm como foco, principalmente, o público adulto. Embora o interesse pelas crianças, suas práticas e preferências de consumo, venha aumentando, ainda não existe um conjunto de conhecimentos ou um campo de estudos sobre o tema (COOK, 2008).

Segundo John (I999), desde meados da década de I970, pesquisadores já exploravam o conhecimento das crianças sobre marcas, produtos, preço, influência na decisão de compra e negociação, entre outros. Porém, para essa autora, um dos assuntos que geraram interesse para o estudo da sociabilização do consumo foi entender a percepção das crianças perante as propagandas. Isso se deve, segundo John (I999), à preocupação dos pesquisadores com o poder de influência da mídia e com o caráter injusto da comunicação persuasiva direcionada a esse público, tratado como mais indefeso por causa da falta de desenvolvimento de seu senso crítico.

Já para Preston (2004, p. 365), a propaganda tem uma relação menos perversa com esse público, pois "o papel macro da propaganda é educar a próxima geração sobre o consumo". Isso é o que o autor chama de sociabilização da economia e que John (I999) estuda como sociabilização para o consumo. Pres- 
ton (2004, p. 365) afirma ainda que "as crianças usam isso [a propaganda] para aprender as ferramentas de interação social que facilitarão a autoexpressão e a conformidade social".

A relação entre crianças e propaganda já foi abordada em estudos sobre comida e obesidade, consumo abusivo de álcool, uso de cigarros, conhecimento de marcas, relação dos filhos com os pais no processo de decisão de compra, materialismo, infelicidade e outras consequências para o bem-estar infantil (cf. DOTSON; HYATT, 2000, 2005; VALKENBURG; CANTOR, 200I; BUIJZEN; VALKENBURG, 2003; VALKENBURG; BUIJZEN, 2005; DESMOND et al., 2007; ROBERTS; PETTIGREW, 2007; BOYLAND et al., 2008; PAGE; BREWSTER, 2009), assim como em estudos genéricos sobre o efeito da propaganda nas crianças (NIAS, I98I; MOSCHIS; MOORE, I982; DESMOND et al., 2007).

Com base em estudos feitos entre I974 e I99 8 sobre assuntos diversos relacionando as crianças e o consumo, tais como marca, preço, distribuição, valores materialistas, e também sobre propaganda, John (I999) concluiu que existem diferenças de percepções entre as propagandas e as outras ações de marketing em crianças de diferentes faixas de idade e de desenvolvimento cognitivo. Para o foco deste artigo, interessam-nos mais as questões de reconhecimento da intenção da propaganda que, segundo essa autora, acontece quando as crianças têm mais de 8 anos. Nessa fase, elas "não mais acreditam que os comerciais digam sempre a verdade” (JOHN, I999, p. I89). E somente entre II e I6 anos, o entendimento das técnicas e dos apelos da publicidade está desenvolvido, como se pode perceber no Quadro I.

\section{QUADRO I}

\section{CONHECIMENTOS DAS CRIANÇAS SOBRE PROPAGANDA}

\begin{tabular}{|c|c|c|c|}
\hline TÓPICO & $\begin{array}{l}\text { ESTÁGIO PERCEPTUAL } \\
\text { (3-7 ANOS) }\end{array}$ & $\begin{array}{l}\text { ESTÁGIO ANALÍTICO } \\
\text { (7-11 ANOS) }\end{array}$ & $\begin{array}{l}\text { ESTÁGIO REFLEXIVO } \\
\text { (11-16 ANOS) }\end{array}$ \\
\hline $\begin{array}{l}\text { Conhecimento } \\
\text { sobre } \\
\text { propaganda }\end{array}$ & $\begin{array}{l}\text { - Consegue } \\
\text { distinguir } \\
\text { propagandas } \\
\text { de programas } \\
\text { com base em } \\
\text { características } \\
\text { perceptuais. } \\
\text { - Atitudes positivas } \\
\text { em relação à } \\
\text { propaganda. }\end{array}$ & $\begin{array}{l}\text { - Consegue distinguir } \\
\text { propagandas de } \\
\text { programas com base } \\
\text { na intenção persuasiva. } \\
\text { - Acredita que a } \\
\text { propaganda mente } \\
\text { e é parcial, mas não } \\
\text { usa essas "defesas } \\
\text { cognitivas". } \\
\text { - Atitudes negativas em } \\
\text { relação à propaganda. }\end{array}$ & $\begin{array}{l}\text { - Entende a intenção } \\
\text { da propaganda, assim } \\
\text { como técnicas e apelos } \\
\text { específicos. } \\
\text { - Acredita que a } \\
\text { propaganda mente e } \\
\text { consegue identificar } \\
\text { exatamente onde elas são } \\
\text { parciais ou enganadoras. } \\
\text { - Atitude cética em relação } \\
\text { à propaganda. }\end{array}$ \\
\hline
\end{tabular}


Duas considerações são importantes a respeito desses estágios. Primeiro, antes dos 8 anos (ainda no estágio perceptual), as crianças já foram atingidas por inúmeras mensagens mercadológicas, não apenas da propaganda, mas também dentro de lojas, supermercados, shoppings etc., pois normalmente acompanham desde cedo seus pais nas compras. Além da idade, a comunicação com os pais é um dos fatores que podem contribuir para uma maior influência das propagandas (e das mídias), assim como os amigos e o tempo de exposição à TV (JOHN, I999). Segundo, as crianças acima de 8 anos (e até mesmo adultos), mesmo possuindo defesas cognitivas contra a persuasão da propaganda, podem não usálas. Preston (2004) afirma que as crianças mostram atitudes positivas ante as propagandas, mesmo não acreditando no que elas dizem.

Em suma, a literatura sobre as crianças e o consumo, com foco na propaganda, mostra que a discussão e reflexão sobre a influência e efeitos dessa comunicação com o público infantil ainda são necessárias. Apesar de uma abordagem crítica da propaganda para crianças ser uma recomendação comum nos artigos que tratam sobre o tema, essa reflexividade ainda não se mostra comum na literatura. Nossa pesquisa procura suprir, ao menos em parte, essa lacuna.

\section{MÉTODO}

\subsection{OBJETO DE ESTUdO E COLETA DE DADOS}

Para analisar empiricamente nosso problema de pesquisa, escolhemos uma marca de produtos direcionados às crianças, a partir da qual pudéssemos identificar ações de marketing em que aspectos relacionados à ambiguidade criança/ adulto estivessem presentes. Após analisarmos diversas marcas, escolhemos a Lilica Ripilica, pois trata-se de uma importante marca destinada exclusivamente ao público infantil. Além disso, suas ações de marketing se mostraram bastante apropriadas para a discussão do nosso problema de pesquisa. A Lilica Ripilica é uma marca de roupas para meninas de $\circ$ a Io anos pertencentes às camadas médias e altas da sociedade brasileira. Ela se encontra atualmente em fase de internacionalização, tendo sido criada em I99I pelo grupo Marisol, um grande grupo empresarial de Santa Catarina, com receita de 453 milhões de reais em 2008 (MARISOL, 2008).

Buscamos dados relativos às duas últimas campanhas de comunicação da marca Lilica Ripilica (outono/inverno 2008 e primavera/verão 2008/2009), incluindo comunicação externa (outdoor), catálogos, material impresso e vídeos, além de outros materiais disponíveis na internet que pudessem auxiliar a nossa 
pesquisa. Ainda que tenhamos analisado todos os dados, somente os itens mais representativos/relevantes para os propósitos deste artigo serão aqui analisados.

\subsection{ANÁLISE DOS DADOS}

Segundo Bauer e Gaskell (2003, p. 244), "análise de discurso é o nome dado a uma variedade de diferentes enfoques no estudo de textos, desenvolvida a partir de diferentes disciplinas". Essas autoras citam mais de 57 variedades de análise, mas discutem apenas três. Entre elas, está a linguística crítica, uma variedade preocupada com a relação entre linguagem e política. Segundo Fairclough (200I, p. 9I), "o discurso é uma prática não apenas de representação do mundo, mas de significação do mundo, constituindo e construindo o mundo em significados". Esses significados representados e constituídos por meio do discurso constroem a identidade social e a relação entre as pessoas, além dos sistemas de conhecimento e crença (FAIRCLOUGH, 200I).

Para Blommaert e Bulcaen (2000), a análise crítica de discurso (ACD) é uma escola recente de análise de discurso que se preocupa com as relações de poder e desigualdade na linguagem. Eles mostram que a ACD considera o discurso como construído e condicionado socialmente. Além disso, o discurso é um objeto de poder obscuro na sociedade moderna e a ACD tem como objetivo tornar isso visível e transparente (BLOMMAERT; BULCAEN, 2000).

Assim, a diferença entre análise de discurso e análise crítica de discurso está, principalmente, no foco da ACD nas relações de poder (como é criado o discurso) e no contexto social que é trazido para auxiliar e contextualizar a interpretação. Já a análise de discurso fica mais focada no que Fairclough (1995) chama de análise textual - a descrição do discurso (escrito ou falado) focado principalmente na linguística.

Portanto, adotamos a análise crítica de discurso, conforme proposto por Fairclough (200I), dada a sua afinidade com nosso objetivo de pesquisa, já que ela vai além de outras formas de análise de discurso, por levar em consideração o contexto social do discurso e as relações de poder envolvidas. Segundo Fairclough (200I), o discurso é tridimensional e sua análise deve ser feita, portanto, em três etapas: a análise textual (uma "descrição" dos dados, metáforas utilizadas, coesão etc.), a análise processual (que compreende a análise conjunta dos textos e da prática discursiva - produção, distribuição e consumo do discurso) e a análise social (que busca a compreensão dos efeitos socioculturais da prática discursiva em questão). 


\section{RESULTADOS}

Passamos agora para a análise do discurso "ações de marketing da empresa Lilica Ripilica". Seguimos, para isso, o ordenamento metodológico proposto por Fairclough (I995), utilizando a etapa de análise textual para trabalhar com a ação de marketing normalmente denominada de campanha de comunicação. Em seguida, na etapa processual, investigamos mais a fundo a constituição do discurso "estilo Lilica" pelo marketing e, por fim, apresentamos a análise social do discurso da Lilica Ripilica e discutimos os reflexos e as consequências sociais deste.

\subsection{ANÁLISE TEXTUAL - AS CAMPANHAS DE COMUNICAÇÃO}

A marca Lilica Ripilica busca estabelecer uma forte ligação com o mundo da moda. Essa ligação pode ser observada de várias formas, seja no discurso publicitário, seja na linguagem apresentada nas outras formas de interação que a marca procura ter com o seu público. De maneira geral, a marca procura conduzir sua comunicação diretamente ao seu público (infantil, feminino, camadas médias e altas), por meio de uma linguagem que caracteriza a marca Lilica Ripilica, frequentemente representada por uma mascote, como uma das crianças, uma "amiguinha". Como mascote, a empresa usa um coala, animal característico da Austrália, vestido como uma criança do sexo feminino. Essa mascote tem o mesmo nome da marca. Vamos, então, descrever e analisar um pouco as campanhas de comunicação da Lilica Ripilica.

Em um outdoor da campanha inverno 2008, a mensagem "Use e se lambuze" é apresentada de maneira quase centralizada no espaço. Ocupando o lado esquerdo, encontramos a foto de uma menina aparentando cerca de 4 ou 5 anos. No canto inferior direito, como uma assinatura, está o nome da marca: Lilica Ripilica. De maneira geral, as imagens contidas no outdoor transmitem a ideia de sofisticação. A menina aparece maquiada, com expressão séria e pose que faz referência às propagandas de moda para adultos. Sua roupa se constitui de uma camiseta, um casaquinho - tipo bolero - e uma saia. A mascote aparece de maneira discreta, seja na estampa da camiseta, seja no brasão costurado ao casaquinho sobreposto. O clima de sofisticação se estende para a bem combinada estampa da saia e da gola do casaquinho, a estampa de fundo do outdoor, dando ideia de um papel de parede, além da fonte usada no texto, que lembra fonte cursiva, como se alguém tivesse escrito com uma caneta tinteiro.

A mensagem nesse outdoor - "Use e se lambuze" - é usada no imperativo, como é comum no discurso publicitário. Essa mensagem parece estar primei- 
ramente ligada ao conceito de chá da tarde (a menina segura um doce na mão esquerda e sua boca está um pouco lambuzada por esse doce), mais especificamente com as brincadeiras de chá com bonecas. Podemos concluir (possivelmente como também devem ter imaginado os responsáveis pela campanha) que, assim como as crianças (literalmente) se lambuzam com os doces nos chás, as meninas deveriam "se lambuzar" (aproveitar) com essa coleção. É importante, ainda, enfatizar a sutil conotação erótica da propaganda, uma vez que o verbo lambuzar está, ao menos no Brasil, culturalmente associado a questões sexuais, entre outros sentidos mais literais da palavra. Por conta dessa associação erótica, a exibição desse outdoor gerou um processo do Ministério Público do Estado de Santa Catarina, que comprometeu a empresa e obrigou-a a não mais veicular propaganda com imagens como a do outdoor em questão, além do pagamento de multa no valor de vinte mil reais, segundo o Instituto Alana (2008).

As imagens do catálogo da coleção inverno 2008 seguem o tema chá da tarde, mostrando as meninas vestidas com sofisticação, em cenário que lembra uma decoração europeia, com papel de parede, móveis antigos, entre outros. As expressões das meninas são normalmente sérias, voltadas para quem vê o catálogo e, quando em interação com os doces, parecem oferecer o doce a quem vê o catálogo, ou estão prestes a comê-los. Como na maioria das peças do segmento de moda, a comunicação é principalmente visual e o texto traz apenas o nome das peças e suas referências.

Já no catálogo da coleção primavera e verão 2008/2009, notamos uma linguagem corporal, com poses e expressões faciais semelhantes às observadas em catálogos de moda voltados ao público adulto. As meninas raramente aparecem sorrindo. Algumas poses chegam até a apresentar ar romântico e de sensualidade. O contexto espacial não é mais o interior de casas europeias, mas sim ambientes externos bucólicos. O nome da coleção de primavera/verão 2008/2009 é "Beauty Essence" e remete ao perfume das flores, que emprestaria sua essência de beleza para as meninas. Com a coleção, segundo o catálogo da empresa, "perfumadas e cheias de encanto, as meninas passam o verão brincando de ficar ainda mais bonitas". As descrições das roupas trazem uma linguagem aparentemente fora do alcance das crianças e mais direcionada às mães. Porém, nota-se uma preocupação em não excluir as crianças do discurso, por exemplo, na falta de pronomes pessoais nas frases: "das passarelas direto para o dia-a-dia" e "musthave no guarda-roupas”. Ou seja, não há pronome identificando se essas frases são para as crianças (ou seja, no seu dia a dia ou no seu guarda-roupas) ou para as mães (no de sua filha).

Na propaganda para a televisão da campanha de 2008 da marca Lilica Ripilica, uma menina com uniforme de colégio aparece na frente de seu guarda-roupa e, assim que abre as portas, flashes de fotografia e som de várias pessoas tentando 
chamar a sua atenção aparecem. A menina dá autográfo para uma das mãos que surgem com papel e caneta, depois solta o cabelo e posa para fotos. No final, já sem o uniforme, aparece maquiada, de vestido, bolsa, e com os cabelos soltos. Após, seu quarto vira uma passarela e ouvem-se palmas e gritos. No encerramento, aparecem a marca, ilustrada com a mascote, e a frase: "Lilica Ripilica. Mais que um sonho", que é falada em off por uma locutora (a voz é de uma mulher adulta). Mais uma vez, o discurso é composto mais por elementos visuais, que contam uma história, em uma estrutura narrativa com foco na escolha da roupa da personagem. A história é resumida na frase final "mais que um sonho", que traz a ideia de que ser famosa, ter atenção e se vestir bem é mais que um sonho para a personagem, pois ela veste Lilica Ripilica. Muito do discurso fica subentendido, deixando espaço para a interpretação de quem assiste à propaganda.

Já no caso da propaganda impressa, as mensagens são mais diretas. Modelos adultas aparecem tentando (literalmente) vestir as roupas da marca Lilica Ripilica, apresentando, em certo aspecto, um discurso de superioridade das crianças (meninas) em relação às mulheres adultas, decorrente do fato de estas poderem usar roupas menores, serem mais magras e estarem na moda. As mensagens publicitárias da campanha incluem sempre a frase de acabamento "Lilica Ripilica. Proibida para maiores", e diferentes fotos temáticas se apresentam a partir das seguintes chamadas: "Não é fácil entrar no mundo da moda"; "Sua filha sonha em ser modelo. E as modelos sonham em ser sua filha"; "É por isso que top model vive tentando emagrecer"; "Um dia você vai crescer e ter um corpão. Aproveite agora"; "Top models, morram de inveja”; "Top models são altas e de pernas longas. Azar o delas"; e "Infância nunca sai de moda".

As mensagens publicitárias, portanto, reforçam a ideia de que a marca aproxima as meninas para o mundo das top models (mundo da moda, ser modelo, emagrecer, "corpão", sair de moda). A tal superioridade das crianças, portanto, não está relacionada a caracterizações da vida infantil contemporânea (mesmo que mais restrita a camadas médias e altas), como ter tempo para brincar, ser protegida pela sociedade (família, Estado, escola). O que está sendo reforçado nessas mensagens é uma superioridade de atributos adultos (mais especificamente atributos sociais do feminino), os quais essas crianças que consomem Lilica Ripilica poderão ter.

\subsection{ANÁLISE PROCESSUAL DO DISCURSO - 0 ESTILO LILICA}

A marca Lilica Ripilica foi criada em I99I e pertence ao grupo Marisol, empresa de Santa Catarina fundada em I964. A análise do site mostra que a marca Lilica Ripilica tem como público-alvo meninas de o a Io anos, pertencen- 
tes à classe A (LILICA RIPILICA, 2008). Segundo o site da empresa, a marca tem mais de I5 anos de mercado e atualmente está em fase de internacionalização.

Conforme já apresentado, a marca tem uma mascote, uma coala, animal característico da Austrália, vestida como uma criança do gênero feminino. Uma questão importante sobre essa mascote se refere à recente remodelação de seu desenho. Primeiramente, a mascote tinha contornos mais infantis, mais arredondados e vestia roupa de bailarina. A nova versão da coala identifica-se melhor com uma top model, com as mãos na cintura, imitando uma pose característica que as modelos fazem ao desfilar na passarela. Além disso, ela aparece mais adolescente e mais magra do que o desenho anterior.

Sobre a personalidade ou o "estilo Lilica", o site traz a seguinte definição (grifos nossos):

[...] com uma personalidade única e encantadora, a Lilica Ripilica é uma coala charmosa, alegre e romântica, que adora estar na moda. Ao mesmo tempo em que transmite doçura, sabe ser ousada. Suas coleções já contagiam o mundo da moda há mais de I5 anos. Muito mais que um estilo delicado de cores suaves e tons de rosa, vestir Lilica Ripilica é descobrir novas sensações, despertar sonhos e encantar tudo ao seu redor. As peças coordenáveis, diferenciadas e super confortáveis, deixam o seu visual irreverente e criativo. Ser Lilica é se divertir brincando de se vestir. É um mundo de fantasia onde todos os detalhes se combinam. É passear no shopping, tomar sorvete e conversar com as amigas. A menina Lilica Ripilica sabe o que quer, pois é moderna, autêntica e sofisticada. Ela é diferente e tem estilo, sem perder a inocência e a delicadeza do mundo infantil. Tem atitude, é despojada e gosta de se manter informada sobre as tendências da próxima estação.

Na Triplik, uma revista de divulgação da marca, gratuitamente distribuída nas lojas para as clientes, assim como no site da marca, as meninas podem brincar, sempre tendo a moda como tema. Em uma das brincadeiras do site, pode-se vestir a coala com diferentes estilos, combinando as peças de roupa. Já na revista, a brincadeira é descobrir a frase secreta ("comigo você está na moda”). Há também consultoria de moda e maquiagem, intercalada com lições sobre animais, pintores, dicas de filmes, aula de francês e espaço para envio de fotos e opiniões. Na Triplik, palavras como "antenada", "moderna, "ousada" e "bonita" são associadas e direcionadas para as consumidoras da marca.

No Clube Lilica Ripilica, uma comunidade virtual das consumidoras inspirado no site de relacionamento Orkut, as sócias podem colocar fotos, adicionar amigos, escrever seu diário e concorrer a prêmios. A linguagem do site do clube procura criar intimidade e cumplicidade entre a marca/mascote e a criança 
associada. Além do site, da revista e do clube, a comunicação da empresa inclui ainda investimento em desfiles durante eventos, como São Paulo Fashion Week, Donna Fashion Iguatemi, entre outros. Segundo o site da empresa, recentemente ela também decorou um quarto no resort Blue Tree Park Paradise, em Mogi das Cruzes, São Paulo. Além disso, a marca Lilica Ripilica é licenciada e está presente em cadernos e agendas da marca Tilibra.

Como podemos perceber, a empresa Marisol busca construir uma marca de moda, tendo como parâmetro a construção de marcas voltadas para o público adulto: procura estabelecer fortes vínculos entre as crianças e a marca, usa imagens e linguagem sofisticadas, expõe sua imagem (marca, mascote etc.) em diversos canais de comunicação e em produtos, e, principalmente, dirige-se às crianças, visual ou textualmente, de maneira muito semelhante àquela adotada em marcas destinadas às mulheres adultas.

\subsection{DISCURSO DA LILICA RIPILICA - UMA ANÁLISE SOCIAL}

Nossa análise social está ancorada no processo de "adultização" das representações acerca das consumidoras infantis, retratado nas ações de marketing da marca de vestuário Lilica Ripilica. Além disso, discutiremos os reflexos das ações de marketing dessa empresa a partir da ótica de organizações especialistas em direitos de crianças e adolescentes, tais como o Instituto Alana.

Primeiramente, sobre a questão da adultização, temos que as ações de marketing da empresa de vestuário infantil Lilica Ripilica estão fortemente ligadas a um contexto etário referente à vida adulta e, com maior ênfase, a um determinado arquétipo de vida adulta do feminino. A ideia de que os usuários da marca seriam pessoas ligadas à moda, por exemplo, está na reformatação da mascote e na caracterização de sua personalidade como alguém que adora estar na moda e que apresenta postura madura. Essas ideias, na realidade, permeiam todas as formas de comunicação da empresa.

De forma complementar, as ideias de sonhos e de encantamento, fortemente ligadas à aspiração hoje comum das meninas em se tornarem modelos, também são uma constante na comunicação da Lilica Ripilica. Nessa comunicação, as crianças também são representadas e tratadas como adultos. Por exemplo, em sua definição de estilo, a marca afirma sua visão sobre a criança como alguém "que sabe o que quer". Portanto, uma visão coincidente com a literatura recente a respeito do consumo infantil, que identifica como traço característico dos publicitários a quebra do "velho código de inocência infantil" (CROSS, 2002, p. 442).

A quebra desse "código", entretanto, ainda não é aceita socialmente de maneira explícita. Uma demonstração disso é que, em entrevista para o jornal 
Zero Hora, a produtora de moda do desfile da marca no evento Donna Fashion Iguatemi, Madeleine Müller, cita que "o que de pior se pode explorar em uma coleção infantil é a sensualidade. Expor o corpo de uma criança de maneira inadequada é abominável. Nem elas gostam" (SHOW MIRIM, 2008). Porém, as informações empíricas anteriormente apresentadas contradizem esse discurso da produtora, como no outdoor da campanha da Lilica Ripilica que descrevemos na seção referente à análise textual.

Nossa conclusão de que o discurso da produtora do desfile não condiz com a prática da empresa não é infundada. O Instituto Alana (2008), em seu site, reforça nossa conclusão ao apresentar o parecer da psicóloga Maria Helena Masquetti, anexado à denúncia feita ao Ministério Público em decorrência da exibição do referido outdoor. Em seu parecer, a psicóloga comenta que

[...] algumas publicidades vão ainda mais além, divulgando conceitos dissociados da realidade, muitos deles distorcendo valores fundamentais para a educabilidade dos pequenos, importando-se apenas em destacar a mensagem na paisagem publicitária (INSTITUTO ALANA, 2008).

Ela ainda acrescenta, em sua análise para o Instituto, que nada é tão capaz de cativar a atenção do que "crianças em cenários afetivos ou demonstrando graça e esperteza em suas expressões”. Segundo a psicóloga, ainda mais "interessante" é quando elas se comportam como uma espécie de adulto em miniatura, pois, se essas estratégias têm o poder de seduzir adultos, elas são ainda mais sedutoras para crianças e adolescentes. O problema com esse tipo de comunicação é que, para seu entendimento, é necessária uma estrutura intelectual que não está ao alcance das crianças ou que, pelo menos, não se identifica no público em geral, e menos ainda nas crianças. Maria Helena Masquetti conclui:

[...] um adulto pode até compreender que a expressão "Use e se lambuze" faz uma analogia entre o doce com o qual a pequena provavelmente lambuzou o rosto e a idéia de se deliciar com o uso da roupa. Este tipo de mensagem ambígua não é decodificável por uma criança preservada em sua ingenuidade, restando a possibilidade incômoda de ser lida maliciosamente por adultos inescrupulosos. Portanto, trata-se de uma construção pautada em valores e conceitos adultos e não infantis (INSTITUTO ALANA, 2008).

É importante analisar, entretanto, que a própria fala da psicóloga Maria Helena Masquetti está amparada em uma conceituação sócio-histórica das cate- 
gorias etárias que diferencia as crianças (ingênuas) dos adultos (inescrupulosos e maliciosos). Na fala da psicóloga, está bastante presente a ideia de que as crianças não apresentam uma estrutura intelectual capaz de interpretar, por exemplo, mensagens ambíguas como a da propaganda em análise. A criança é, portanto, um sujeito distinto do adulto e cuja "construção" deve ser preservada de valores e conceitos "não infantis", para que, enfim, ela seja uma criança e não um adulto em miniatura (POSTMAN, I999).

Além da imagem de erotização apresentada na campanha do outdoor, outras comunicações também se valem de outros argumentos sedutores ou que poderiam ser facilmente voltados ao público adulto. Relembrando, a coleção de inverno da Lilica Ripilica do ano de 2008 tinha como tema um chá da tarde inglês. As roupas, os emblemas, cortes e tecidos buscavam lembrar a sofisticação e a elegância das coleções europeias. Além disso, o fato de as meninas apresentadas nas diversas peças publicitárias estarem vestidas com roupas características de pessoas mais velhas, assim como com maquiagem e fazendo poses normalmente vistas em propagandas com mulheres de mais idade, serviram de base para a denúncia da campanha como incitadora da "adultização" e, principalmente, da "erotização" infantil, pois, como pode-se perceber, as crianças não aparecem nas imagens brincando ou tendo atitudes tipicamente infantis. Ao contrário, a linguagem corporal e a seriedade das expressões são nitidamente copiadas de coleções direcionadas para mulheres mais velhas.

No caso da propaganda para a televisão, assim como nas imagens da campanha impressa, o discurso da marca é direcionado para a realização do desejo de ser famosa. Ou seja, as propagandas falam que, usando os produtos Lilica Ripilica, ser tão bela e admirada como as modelos é possível, não é um sonho. Esse "sonho", por sua vez, nada mais é do que um arquétipo emocional do feminino adulto contemporâneo (ser modelo, famosa e consumir roupas de marca), na medida em que se refere a "padrões comuns a toda cultura humana [...] elementos simbólicos que resgatam estados de espírito comuns a todos nós" (MARTINS, I999, p. 37). Na propaganda impressa, as expressões de frustração das modelos adultas por não entrarem nas roupas Lilica Ripilica procuram transmitir, em um primeiro momento, um sentimento de superioridade das meninas crianças em relação às mulheres adultas. Entretanto, não são os atributos infantis aqueles que são valorizados (poder brincar, ser socialmente protegida etc.), mas sim a possibilidade de, ao usar Lilica Ripilica, estar mais próxima de atributos do mundo adulto feminino do que as próprias mulheres adultas (estar na moda, ser magra, ser top model etc.).

Além das roupas tipicamente adultas e da ligação com o universo da moda, existe também a menção a padrões estéticos específicos, como a magreza, imprescindível para a entrada da consumidora em questão ao mundo da moda. 
A propaganda para a televisão mostra uma menina que exibe vaidade, arrumando-se, maquiando-se e posando para fotos. Já a campanha impressa valoriza os atributos físicos das modelos (magreza, pernas longas, altura), qualidades determinantes na sociedade contemporânea para se encaixar no conceito de beleza (SANT'ANNA, 200I; GOLDENBERG; RAMOS, 2002; STENZEL, 2004). Como Preston (2004) afirma, a propaganda ensina esses conceitos para as crianças. Um outro exemplo: no catálogo da coleção primavera/verão 2008/2009, as palavras usadas para descrever as diferentes inspirações para a coleção falam de encanto, beleza, romantismo, feminilidade, delicadeza e sofisticação. Essas expressões são comuns na comunicação para adultos e fazem uma ligação entre os mundos infantil e adulto. Assim, identificamos um retorno a características observadas por Ariès (I98I, p. 70) em relação à Idade Média: "nada, no traje medieval, separava a criança do adulto".

Além do traje, observamos nas campanhas também comportamentos, olhares, posturas e mensagens não verbais tipicamente adultos, ligando as ideias de beleza ao mundo da moda. Por exemplo, segundo o jornal Zero Hora, as marcas Lilica Ripilica e Tigor "roubaram a cena no úlitmo dia de desfiles" do Donna Fashion Iguatemi, em sua segunda edição de 2008 . A matéria chama atenção para o fato de que, mesmo fazendo um trabalho "de gente grande", essas meninas e meninos continuam brincando, comendo e se divertindo. Verifica-se pelas entrevistas que as meninas levam esse trabalho mais a sério: "Quero trabalhar com moda, por isso comecei a desfilar” (Bianca, 9 anos) (SHOW MIRIM, 2008).

As consequências desse tipo de discurso, que "ensina" às crianças padrões de beleza e de comportamentos relacionados ao mundo adulto, podem levar a uma "adultização" e erotização precoce desse público, como atesta a psicóloga parecerista do Instituto Alana. Obviamente, não é só a comunicação das empresas que provoca esse tipo de resultado; ele é reforçado em várias das manifestações culturais exibidas na mídia de massa e pelo próprio comportamento das crianças, muitas vezes incentivado por familiares e amigos. Hoje, o senso comum exalta as relações entre beleza, moda e fama. O que a Lilica Ripilica faz é utilizar esses valores associados ao senso comum, e que indiscutivelmente são sedutores, em suas estratégias de comunicação.

Resta-nos questionar os efeitos psicológicos e comportamentais dessa estratégia sobre as meninas consumidoras da marca. Será que elas acreditam que, ao adquirirem as roupas e os acessórios da marca, conseguirão atingir esses ideais do senso comum? Será que elas pensam que, ao tornarem-se consumidoras fiéis da Lilica Ripilica, elas se manterão no mundo da moda e serão admiradas por todos e vistas como adultas, maduras, que "sabem o que querem"? Esses questio-

Tigor refere-se à linha masculina de roupas para crianças da marca Marisol S.A. 
namentos fogem do escopo deste artigo, mas são muito relevantes para análise dos efeitos do marketing sobre as crianças e são aspectos importantes a serem investigados em estudos futuros.

\section{CONSIDERAÇÕES FINAIS}

A análise crítica dos discursos criados e distribuídos pela marca Lilica Ripilica mostra que é necessária uma reflexão, por parte da academia de marketing, das empresas, dos profissionais de marketing e da sociedade, sobre os efeitos do marketing e mais especificamente da comunicação, e sobre os valores transmitidos às crianças.

As ações de comunicação da empresa Lilica Ripilica, agregadas com a análise que especialistas em direitos de crianças e adolescentes (Instituto Alana), demonstraram claramente a ambiguidade (ou pelo menos uma das ambiguidades) que orientam as representações sobre o consumidor infantil na sociedade urbana contemporânea. Enquanto o discurso da marca Lilica Ripilica trabalha com uma ideia de infância que lembra a inexistência de um ideal de criança na Idade Média (ARIÉS, I98I; POSTMAN, I999), o discurso do Instituto Alana resgata um sentido de infância que se constrói a partir dos séculos XVI e XVII, no qual a criança é vista como algo diferente dos adultos, assim como carente de cuidados por parte destes (ARIÈS, I98I; POSTMAN, I999).

Mais especificamente sobre as representações de infância construídas nas ações de marketing da marca Lilica Ripilica, percebemos que estas nos remetem ao mesmo fenômeno de indissociação da vida infantil da vida adulta observado na Idade Média por Ariès (I98I). Se indícios desse fenômeno foram citados por Postman (I999), e outros autores já vinham notando esses indícios em outras áreas como a psicologia (SILVA, 2006) e o desenho de moda (BARBOSA; QUEDES, 2007), podemos, como base nas conclusões obtidas em nossa pesquisa, entender que esse fenômeno aparece hoje ainda mais consolidado. As ações de marketing da empresa analisada refletem, em seus discursos, essa criança-adulta com acesso à informação, autossuficiente em suas decisões, com comportamentos, posturas, pensamentos e atividades profissionais de adultos.

Cabe destacar, entretanto, uma importante diferença entre a indissociação da vida infantil e adulta ocorrida na Idade Média, e analisada por Ariès (I98I), e esta que se apresenta no contemporâneo, que nosso estudo ajuda a compreender. Na Idade Média, o contexto histórico-cultural que ajudava a construir essa indistinção se referia a pouca esperança em relação à sobrevivência das crianças (ARIÈS, I98I). A contribuição do nosso trabalho se refere à observação dessa mesma indissociação, porém, a partir de outra perspectiva: a adultização de 
crianças como forma de sociabilização destas para o mercado de consumo. Ou seja, o contexto histórico-cultural no qual a categoria infância começa a ser "adultizada" se refere a valores sociais baseados no consumo como forma de inserção social e construção de identidades (JOHN, I999).

Portanto, as crianças se apresentam como um novo "mercado" a ser explorado, e, para isso, os discursos que permeiam tais ações de marketing estão baseados no pressuposto de que elas "têm o direito" de fazer parte do mercado de consumo ou, em outras palavras, de ser adultos. Um novo modelo de adulto em miniatura parece se construir.

Assim, com este artigo, esperamos ter trazido um convite à reflexão sobre as consequências das ações de marketing, principalmente da propaganda, sobre o público infantil. Nesse sentido, futuras pesquisas com as próprias crianças podem explorar limitações deste artigo, como a ausência de coleta de dados de outras empresas e, principalmente, a análise da percepção das próprias crianças sobre o fenômeno que analisamos. Isso é imprescindível para um estudo mais preciso a respeito da indistinção da vida infantil e da adulta, algo que nos parece cada vez mais acentuado na sociedade contemporânea e que vem sendo influenciado pelo marketing.

\section{REFERÊNCIAS}

ARIÈS, P. História social da criança e da familia. Rio de Janeiro: LTC, I98I.

BARBOSA, R.; QUEDES, W. Vestuário e infância. In: ENCUENTRO LATINOAMERICANO DE DISEÑO, 2., 2007, Buenos Aires. Anais... Buenos Aires: Universidad de Palermo, 2007.

BAUER, M. W.; GASKELL, G. Pesquisa qualitativa com texto, imagem e som. Petrópolis: Vozes, 2003 .

BLOMMAERT, J.; BULCAEN, C. Critical discourse analysis. Annual Review of Anthropology, Palo Alto, v. 29, p. 447-466, 2000.

BOYLAND, E. J. et al. Does television food advertising affect children's food preferences? Appetite, v. 5I, n. 3, p. 760-760, 2008.

BUIJZEN, M.; VALKENBURG, P. M. The effects of television advertising on materialism, parentchild conflict, and unhappiness: a review of research. Journal of Applied Developmental Psychology, College Park, v. 24, n. 4, p. 437-456, 2003.

COOK, D. T. The missing child in consumption theory. Journal of Consumer Culture, Oxford, v. 8, n. 2, p. 219-243, July, 2008.

COWELL, P. Marketing to children: a guide for students and practitioners - part I. The Marketing Review, Germantown, v. I, p. 473-485, 200 I.

CROSS, G. Valves of desire: a historian's perspective on parents, children and marketing. Journal of Consumer Research, Chicago, v. 29, p. 44I-447, 2002.

DESMOND, R. et al. The effects of advertising on children and adolescents: a meta-analysis. Mahwah, NJ: Lawrence Erlbaum, 2007. 
DOTSON, M. J.; HYATT, E. M. A comparison of parents' and children's knowledge of brands and advertising slogans in the United States: implications for consumer socialization. Journal of Marketing Communications, London, v. 6, n. 4, p. 219-230, 2000.

Major influence factors in children's consumer socialization. Journal of Consumer Marketing, Anvada, v. 22, n. I, p. 35-42, 2005.

FAIRCLOUGH, N. Critical discourse analysis: the critical study of language. London: Longman, I995.

Discurso e mudança social. Brasília: Editora UnB, 200I.

GOLDENBERG, M.; RAMOS, M. S. A civilização das formas: o corpo como valor. In: GOLDENBERG, M. (Org.). Nu \& vestido. Rio de Janeiro: Record, 2002.

GUERREIRO, M. das D.; ABRANTES, P. Como tornar-se adulto: processos de transição na modernidade avançada. Revista Brasileira de Ciências Sociais, São Paulo, v. 20, n. 58, p. I57-I75, 2005.

HEYWOOD, C. Uma história da infância. Porto Alegre: Artmed, 2004.

INSTITUTO ALANA. Denúncia outdoor Marisol. Disponível em: <http://www.alana.org.br/ CriancaConsumo/AcaoJuridica.aspx?v=I\&id=52>. Acesso em: I3 out. 2008.

JOHN, D. R. Consumer socialization of children: a retrospective look at twenty-five years of research. Journal of Consumer Research, Chicago, v. 26, n. 3, p. I83-213, I999.

LAJOLO, M. Infância de papel e tinta. In: FREITAS, M. C. de (Org.). História social da infância no Brasil. São Paulo: Cortez, I997.

LILICA RIPILICA. Disponível em: <htpp://www.lilicaripilica.com.br>. Acesso em: I3 out. 2008.

MARISOL. Demonstrativo financeiro 2008. Disponível em: <http://www.marisolsa.com.br/ relacao_investidores/demonstrativo_financeiro_2008.pdf>. Acesso em: I5 jun. 2008.

MARTINS, J. A natureza emocional da marca: como encontrar a imagem que fortalece sua marca. São Paulo: Negócio, I999.

MCCRACKEN, G. Culture and consumption: a theoretical account of the structure and movement of the cultural meaning of consumer goods. Journal of consumer research, Chicago, v. I3, p. 7I-84, June I986.

MOSCHIS, G. P.; MOORE, R. L. A longitudinal study of television advertising effects. Journal of Consumer Research, Chicago, v. 9, n. 3, p. 279, I982.

NIAS, D. K. B. The effects of television advertising on children. Behaviour Research and Therapy, v. I9, n. 6, p. 560-560, I98I.

PAGE, R. M.; BREWSTER, A. Depiction of food as having drug-like properties in televised food advertisements directed at children: portrayals as pleasure enhancing and addictive. Journal of Pediatric Health Care, v. 23, n. 3, p. I50-157, 2009.

POSTMAN, N. O desaparecimento da infância. Rio de Janeiro: Graphia, I999.

PRESTON, C. Children's advertising: the ethics of economic socialization. International Journal of Consumer Studies, Caerphilly, v. 28, p. 364-370, Sept. 2004

PRIORE, M. D. (Org.). História das crianças no Brasil. São Paulo: Contexto, 2000.

ROBERTS, M.; PETTIGREW, S. A thematic content analysis of children's food advertising. International Journal of Advertising, Milton Park, v. 26, n. 3, p. 357-367, 2007.

SANT'ANNA, D. Corpos de passagem: ensaios sobre a subjetividade contemporânea. São Paulo: Estação Liberdade, 200I.

SHOW MIRIM. Zero Hora, Porto Alegre, 29 set. 2008. Caderno Donna Fashion Iguatemi, p. I. 
SILVA, C. M. Infância: desafios da modernidade. In: ENCONTRO DE PSICOLOGIA DE ASSIS, I9., 2006, Assis. Anais... Assis: Unesp, 2006.

STENZEL, L. M. Servir (vir a ser): o imperativo do corpo magro na contemporaneidade. In: STREY, M. N.; CABEDA, S. T. L. (Org.). Corpos e subjetividade em exercício interdisciplinar. Porto Alegre: EdiPUCRS, 2004 .

VALKENBURG, P. M.; BUIJZEN, M. Identifying determinants of young children's brand awareness: television, parents, and peers. Journal of Applied Developmental Psychology, College Park, v. 26, n. 4 , p. $456-468,2005$.

VALKENBURG, P. M.; CANTOR, J. The development of a child into a consumer. Journal of Applied Developmental Psychology, College Park, v. 22, n. I, p. 6I-72, 200 I. 